Dossiê: Judaísmo: religião, cultura, nação - Artigo Original

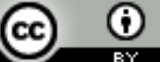

\title{
Abraham J. Heschel e a mística do pathos divino
}

\author{
Abraham J. Heschel and the mysticism of divine pathos
}

Edson Fernando de Almeida *

\begin{abstract}
Resumo
A categoria do pathos divino ganhou em Abraham Heschel sua expressão mais forte. O profeta não tem ideias e conceitos sobre Deus, o profeta é aquele que sofre uma ação transitiva de Deus. Não se trata de uma fusão com Deus, trata-se de ser afetado pelo pathos de Deus. Para Heschel a experiência mística é um êxtase do ser humano; a revelação é um êxtase de Deus. Não é Deus que é uma experiência do ser humano; o ser humano é que é uma experiência de Deus. Deriva daí não uma mística unitiva propriamente, mas uma mística simpatetica, que se traduz como resposta humana às dores de Deus nas dores do mundo. O que testemunham os profetas não é a essência do divino, mas seu pathos, sua concernência com a miséria humana. O pathos divino é como uma ponte lançada sobre o abismo que separa o ser humano de Deus.
\end{abstract}

Palavras-chave: Heschel, pathos divino, teologia profunda, mística.

\begin{abstract}
The category of divine pathos had got its strongest expression in Abraham J. Heschel. The prophet has no ideas and concepts about God, the prophet is one who undergoes a transitive action of God. It is not a fusion with God, it is about being affected by the pathos of God. For Heschel the mystical experience is an ecstasy of human being; revelation is an ecstasy of God. It is not God that is an experience of human being; human being is an experience of God. It derives from this not proper an unitive mystic, but a sympathetic mystic, which translates as a human response to the pains of God in the pains of the world. What the prophets testify is not the essence of the divine, but his pathos, his concern with human misery. The divine pathos is like a bridge thrown over the abyss that separates the human being from God.
\end{abstract}

Keywords: Heschel, divine pathos, deep theology, mysticism.

Artigo submetido em 11 de março de 2019 e aprovado em 29 de abril de 2019.

* Doutor em Teologia pela Pontifícia Universidade Católica do Rio de Janeiro (2002). Professor Adjunto do Departamento de Ciência da Religião da Universidade Federal de Juiz de Fora. País de origem: Brasil. E-mail: edsonfernandodealmeida@gmail.com 


\section{Introdução}

Pelo viver, mais ainda, pelo morrer e ser condenado faz-se um teólogo, não pelo compreender, ler ou especular. (Martinho Lutero).

No início dos anos mil novecentos e noventa tive a oportunidade de conhecer o pensamento do teólogo reformado Jurgen Moltmann. Foi através dele que cheguei à teologia profunda de Abraham Joshua Heschel e seu conceito de pathos divino. Moltmann abraçou de tal sorte a ideia hescheliana do Deus apaixonado que tal noção afetou profundamente sua compreensão trinitária, cristológica e mesmo escatológica. A influência da teologia e filosofia judaicas na teologia de Moltmann não se restringe à figura de Abraham Heschel. O princípio esperança de Ernest Bloch, a singular compreensão da noção de redenção advinda de Franz Rosenszweig, bem como as noções de autolimitação e auto humilhação vindas da antiga teologia rabínica e da tradição cabalística, foram algumas das fontes judaicas do edifício teológico moltmanniano. Mas, a presença do filósofo e teólogo Abraham Heschel teve destaque nessa construção. Em pelo menos seis de seus livros, sobretudo em $O$ Deus crucificado e Experimento Esperança, Moltmann discute a noção de hescheliana de pathos divino.

O livro The Prophets, o seminal texto hescheliano escrito em 1933 como tese de doutorado em filosofia na Universidade de Berlim e reescrito nos anos 1960, em inglês, no contexto do grande movimento da luta pelos direitos civis americanos e na resistência à guerra do Vietnã, expõe com clareza a noção do divino pathos. Para Heschel, os profetas não propunham teorias sobre Deus, os profetas eram testemunhas de uma afecção, de um padecimento. É verdade que a teologia hescheliana espelha a concernência desse pathos em praticamente todos os seus textos, mesmo no primeiro deles, escrito na juventude, antes do trabalho doutoral: Der Shem Hamefoiresh: Mensch - O nome divino: humano (HESCHEL, 2005). Neste livro de poemas que, segundo Alexandre Leone (2002), o próprio Heschel em certo sentido rejeitou - talvez por entender que o seu teor místico poderia 
trazer dificuldades a sua aceitação no mundo acadêmico norte-americano - a noção do pathos divino já se apresenta fortemente.

O primeiro poema do livro Der Shem Hamefoiresch tem título homônimo do livro de Martin Buber, publicado em 1923: Ich und Du (Eu e Tu). Nesse poema a noção do pathos como manifestação da dor divina nas dores do mundo já aponta para o profeta hescheliano como aquele que sofre a dor de Deus nas dores do seu tempo.

Transmissões fluem do teu coração ao Meu, trocando, interligando Minha dor com a tua. Não sou eu mesmo - tu? Não és tu mesmo - eu? Meus nervos estão mesclados com os Teus. Teus sonhos conhecem os meus.

Não somos um nos corpos de milhões?

Muitas vezes eu me vislumbro na forma de cada um, ouço Meu próprio discurso - uma voz quieta, distante no choro de cada um,

Como se sob milhões de máscaras, lá estivesse meu rosto.

Eu vivo em Mim e em ti.

Dos teus lábios, flui uma palavra de Mim para Mim mesmo, Dos teus olhos goteja uma lágrima - cuja fonte está em Mim.

Quando uma necessidade te aflige, clama a mim! Quando sentes falta de um ser humano, chora diante da minha porta!

$\mathrm{Tu}$ vives em ti, tu vives em mim.

(HESCHEL, 2005, p. 31, tradução nossa).

Alexandre Leone vê nesse poema um acoplamento entre o humano e o Divino que, dada a sua intensidade, parece apontar para algo diferente daquele sugerido pelo encontro buberiano Eu-Tu. Esse algo seria precisamente o pathos divino. O humano hescheliano sofre a ação desse pathos e responde simpaticamente a tal sofrimento oferecendo-se como meio pelo qual a compaixão divina vai abraçando um mundo estilhaçado e enfermo. 


\section{Heschel: mística hassídica e dialética}

Como salientou Alexandre Leone (2007), há uma mística judaica refletida na obra de Heschel. Tal mística resulta da recepção que o hassidismo encontra em seus escritos e da dialética que Heschel enxerga e acentua nesta herança hassídica. No livro Passion for Truth, publicado postumamente, Heschel descreve a dialética que absorveu do hassidismo no qual foi criado, do qual foi herdeiro por linhagem sanguínea, ao qual sua teologia profunda prestou um tributo; hassidismo que o forjou e moldou. Moldou-o, segundo Passion for Truth, em uma dialética que seria para Heschel a grande linha a costurar a teologia judaica desde as primeiras escolas do pensamento rabínico.

Eu nasci em Varsóvia, Polônia, mas meu berço de estudo foi Mezbizh (uma pequena cidade na província de Podólia, Ucrânia) onde o Baal Shem Tov, fundador do movimento hassídico, viveu durante os últimos vinte anos de sua vida. Encantado com a riqueza das tradições e contos, eu me sentia verdadeiramente em casa em Mezbizh. De um modo estranho, minha alma se sentia em casa com Baal Shem Tov, mas dirigida pelo Kotzker. Era bom viver com o coração entre a alegria de Mezbizh e a ansiedade de Kotzk? Havia uma vida que eu pudesse escolher para viver? Eu não tinha chance: meu coração estava em Mezbizh, minha mente em Kotzk. (HESCHEL, 1973, p. XIV-XV, tradução nossa).

Os polos da dialética hassídica estão representados por Ball Shem Tov e Menahem Mendl de Kotzk; o primeiro fundador da hassidismo no séc. XVIII, o segundo um dos mais importantes líderes do movimento hassídico no séc. XIX. Eles representam a tensão que de alguma forma costura a história do judaísmo rabínico, a dialética entre a misericórdia e a justiça, o cuidado e crítica, a segurança e a dúvida, a presença e a ausência de Deus no mundo.

Ball Shem Tov fez das trevas horas luminosas; o Kotzker aliviou a miséria e a desolação por avisos prévios, por premonições. O Kotzker restringiume, desmascarando atitudes carinhosas. De Baal Shem Tov eu recebi a dádiva de me adaptar a situações contraditórias. O Baal Shem Tov habitou em minha vida como uma lâmpada, enquanto Kotzker me atingiu como um raio. Para dizer a verdade, o raio é mais autêntico. No entanto, ainda que possa acreditar numa lâmpada, pondo a confiança nela, ninguém pode viver em paz com uma lâmpada. O Baal Shem Tov me deu asas; o Kotzker cercou-me com cadeias. Eu nunca tive coragem de quebrar minhas cadeias e viver alegremente com meus defeitos em mente. (HESCHEL, 1973, p. XIV-XV, tradução nossa). 
Alexandre Leone (2011) nomeou tal dialética com os termos mística e razão e afirma que ela foi amplamente desenvolvida num texto que Heschel escreveu em hebraico: Torá Min Hashamaim Be-Aspaclaria Shel Hadorot. Neste livro a dialética se dá entre Rabi Akiva e Rabi Ishmael, dois paradigmas do judaísmo rabínico de todos os tempos. O primeiro representa o coração, a misericórdia, a poesia que transcende o literalismo escritural; o segundo representa a contextualidade, a historicidade como estrutura da revelação (LEONE, 2014). Akiva é crente, Ishmael é cético. Akiva é poesia, Ishmael é prosa. Akiva é a beleza do mundo, Ishmael é a sua dor. Akiva é a fé que se manifesta em exaltação e emoção, Ishmael é a fé em discrição, claridade e sobriedade. Em Ishmael a Torá fala em linguagem humana, por isso pode conter erros. Em Akiva a Tora fala em linguagem divina, por isso é preciso lê-la com os olhos que vejam o além da letra.

Para Rabi Ishmael a Revelação é divina, mas o texto é humano. Para Akiba o texto humano, porque fruto da revelação divina, aponta para além dele mesmo. Nele há sempre um sentido mais profundo esperando o olhar humano capaz de transcender a mera letra para encontrar a Palavra viva. Ou seja, para Akiba o texto clama por uma hermenêutica mística. A teologia hescheliana espelha tal dialética. Por isso Heschel preferiu chamá-la de teologia profunda, dado o caráter assistemático, pré-conceitual e experiencial de seus escritos. Não por acaso, em Passion for Truth, Heschel dialoga com a filosofia de Kierkegaard. No texto hescheliano, o paradoxo clareza-escuridão, luz-sombra, misericórdia e juízo, finitoinfinito, se mantém no limite. Tal dialética está simbolizada também na disciplina Mística e Ética judaica, que Heschel ministrou ininterruptamente desde que chegou ao Jewish Theological Seminary na metade dos anos 40 até a sua morte em 1972.

Ora, quando nos debruçamos sobre o profeta bíblico, conforme o descreveu Abraham Heschel, o contexto histórico do seu chamado e a consciência de Deus expressos pelas suas palavras registradas escrituristicamente manifestam os termos da dialética que vimos descrevendo acima. Afirma Leone: 
Para Akiva, a Torá originalmente está no céu e o profeta é apenas um instrumento utilizado por Deus para comunicar-se com os homens. O profeta é como uma trombeta soprada por Deus, um instrumento sem nenhuma autonomia. É a voz divina que é escutada quando o profeta fala: o humano é eclipsado durante a experiência da revelação. Portanto, o texto sendo divino é ele mesmo a revelação. Moisés é escrito como subindo aos céus para receber a Torá como na escola de Rabi Akiva. A profecia é a realização da união mística com Deus. Para Rabi Akiva ficar no sentido contextual e simples é perder a profundidade do texto. O dito de Rabi Akiva é que peshat, o método contextual racionalista, tem as mesmas letras que tipesh (tolo). Para a escola de Rabi Ishmael, o profeta é visto como parceiro, sócio de Deus na revelação. A revelação é diálogo entre profeta e Deus e, portanto, há um elemento humano junto com elemento divino no texto bíblico. O profeta não perde sua autonomia nem mesmo na escrita do texto. Para Rabi Ishmael, há passagens da Torá que Moisés teria escrito por sua própria conta e autoridade. Nem todas as passagens da Torá teriam o mesmo nível de revelação. É por isso, portanto, que as palavras refletem o modo humano e as idiossincrasias do idioma. Daí justamente vem a tendência leniente de Rabi Ishmael da interpretacão das leis. Heschel demonstra ao longo de Torá Mim Há-shamaim que estas duas escolas teológicas, racionalista e mística, se desdobraram em diferentes desenvolvimentos nos debates rabínicos por toda a Idade Média até hoje. (LEONE, 2007, p. 77-78).

\section{Profetas e o pathos divino}

A noção hescheliana do pathos divino acentua a dialética mística e razão ao enfatizar a relação entre a concernência divina com os assuntos humanos e a resposta humana a tal concernência: a dimensão simpatética com resposta humana ao pathos divino. O pathos divino, para Heschel, é como uma ponte lançada sobre o abismo que separa o ser humano de Deus. Mas, como tal noção alcançou tamanha centralidade na obra de Heschel? Para Gamberini (2009), é inequívoco que tal noção derive por um lado do estudo que Heschel fez da consciência profética em seu trabalho de doutoramento, de outro lado por sua ligação com a mística hassídica judaica, como vimos acima. Mas, acrescenta a hipótese de que o termo pathos Heschel o tenha absorvido sobretudo de Kierkegaard, ainda que não o afirme explicitamente em nenhum escrito.

Embora o significante pathos não apareça em Passion for truth, seu sentido lá está na compreensão que Heschel tem de Kierkegaard. O filósofo judeu reserva oito dos dez capítulos da obra para tecer detalhada comparação entre os escritos e a biografia de Kierkegaard e Menahem Mendl de Kotzk, o Kotzker. Ainda jovem, Heschel conheceu a obra de Kierkegaard e percebeu que muitos dos seus 
pensamentos lhe eram familiares, pois boa parte das noções básicas kierkegaardianas, Heschel já recebera dos ensinos de Kotzker. Ambos, Kotzker e Kierkegaard, o influenciaram fortemente na juventude (Heschel, 1973).

Reconhecendo, pois, como fontes da teologia profunda de Heschel as nascentes do profetismo bíblico, da mística hassídica e da noção kierkegaardiana de pathos, dediquemo-nos agora, para os efeitos deste artigo, à centralidade do elemento profético e sua noção de pathos divino. Quem são, para Heschel, os profetas bíblicos? São modelos de sensibilidade religiosa que canalizam "a compaixão divina à dor humana” (LEONE, 2002, p. 31). Na primeira frase da introdução do livro The Prophets, diz Heschel:

Este livro é sobre algumas das pessoas mais perturbadas que já existiram: homens cuja inspiração trouxe a Bíblia para dentro do ser - homens cuja imagem é nosso refúgio na aflição e cuja voz e visão sustentam nossa fé. O mais importante não é o que eles disseram, mas o que eles foram. Nós não poderemos entender o que eles quiseram dizer-nos a menos que despertemos para o que aconteceu com eles. Os momentos que viveram não são agora avaliáveis e não podem tornar-se objeto de análise científica. Tudo que temos é a consciência desses momentos preservada em palavras. (HESCHEL, 2001, p. 2, tradução nossa).

Mas, o que é característico da consciência profética? Sua profunda e radical sensibilidade ao mal. Para Heschel, um estudante de filosofia que se voltasse aos discursos dos profetas se sentiria como se estivesse indo do reino sublime a um mundo de trivialidades. Ao invés de lidar com as questões intemporais do vir a ser, matéria e a forma, os profetas lançariam tal estudante para dentro de orações sobre viúvas e órfãos, sobre corrupção de juízes e as trapaças nos negócios. "Ao invés de nos levar às elegantes mansões da alma, os profetas nos levam aos cortiços.” (HESCHEL, 2001, p. 3, tradução nossa).

Para nós um simples ato de injustiça - trapaça nos negócios, exploração do pobre - é desprezível e sem importância; para os profetas isto é um desastre. Para nós a injustiça é uma injúria para o bem-estar do povo; para os profetas é um golpe mortal na existência: para nós um episódio; para eles, uma catástrofe, uma ameaça para o mundo. (HESCHEL, 2001, p. 4, tradução nossa). 
Segundo Heschel, nossos olhos são testemunhas da insensibilidade humana, mas nosso coração tenta de todas as formas esquecer a cena de tal insensibilidade a fim de acalmar os nervos e silenciar a consciência. O profeta, ao contrário,

é um homem que sente furiosamente. Deus acendeu uma chama em sua alma, ele está abatido e atordoado ante a ganância feroz do homem. Assustadora é a agonia do homem, nenhuma voz humana pode canalizar todo esse terror. Profecia é a voz que Deus emprestou à silenciosa agonia, uma voz aos pobres saqueados, às riquezas profanadas do mundo. E uma forma de viver, uma encruzilhada entre Deus e o homem. Deus está furioso nas palavras dos profetas. (HESCHEL, 2001, p. 5-6, tradução nossa).

A essa conexão da ira divina - expressão negativa para dizer a positividade da compaixão - às dores do humano e da criação, Heschel chamou de pathos divino. Os profetas não eram pensadores de Deus, não tinham noções sobre Deus, não faziam abstrações sobre o divino. Os profetas experimentavam o pathos divino. Não o buscavam, sequer o quiseram e mesmo fugiram dele; foram afetados por ele. O que o profeta conhece de Deus não advém de provas ou silogismos. O profeta sofre, é afetado por uma presença. Por isso sua linguagem é poética, intuitiva, assistemática, emocional. A aparente histeria do discurso profético, que parece desprovido de racionalidade, é uma forma de dizer que Deus se dirige ao mundo humano na manifestação de um cuidado. A linguagem metafísica está fora da cena literária do profetismo bíblico (ALMEIDA, 2015).

Se tal linguagem aparece é, segundo Leone, para denotar o sentido das ações humanas e a importância do viver dos homens. O que testemunham os profetas não é a essência do divino, mas seu pathos, sua concernência com a miséria humana. Daí a linguagem fortemente emocional do profetismo bíblico a expressar uma compaixão que se queima pelos seres humanos.

O estilo do discurso profético revela não a essência metafísica de Deus, mas antes e sobretudo o interesse "emocional" divino para com a situação humana. A forma do discurso profético é emocional, seu tema é a vida de todo o povo. Essa vida das pessoas é mesma coalhada de contradições. $\mathrm{E}$ essas contradições vão também se refletir na preocupação divina, que por um lado afirma a importância do homem para Deus; e por outro lado condena e repreende a injustiça, a idolatria e mesquinhez da sociedade humana. (LEONE, 2002, p. 102-103). 
Portanto, Deus como essência não é objeto da experiência profética como o é para a teologia clássica em seu afã por lançar seu logos sobre os atributos e propriedades divinas. O objeto da experiência profética são as manifestações do divino, seu movimento em direção ao mundo: seu pathos. Os profetas não tinham ideias ou teorias sobre Deus. Tinham o que Heschel chamou de understanding. O entendimento que tinham de Deus não era fruto de inquirições sobre o ser divino, era testemunho de sua presença na história. Por isso, os profetas testemunhavam atitudes de Deus, mais do que ideias sobre Ele (HESCHEL, 2001).

Assim, em contraste com o conhecimento especulativo, a atitude profética é mais intuitivo-pensativa e, dado que Deus é apreendido através de suas sensíveis manifestações, tal conhecimento dEle pode ser melhor expresso pelo uso do termo inglês undesrtanding, ou o termo alemão verstannis (HESCHEL, 2001, p. 287). Por isso não há nada nos registros escriturísticos proféticos que se compare a uma teologia sistemática, um tratado dogmático, um conjunto de verdades sobre Deus. Os profetas testemunham a presença divina nas trivialidades da história, jamais argumentam sobre alguma pretensa natureza do Deus a quem experimentam.

Desta forma, a compreensão helenizada do Deus de Israel, tão presente na tradição filosófica ocidental, é imprópria para referir-se ao Deus dos profetas, cujo revelar-se nunca se dá num absolutismo abstrato, mas sempre numa relação íntima com o mundo. O Vivente não ordena e espera obediência. Ele se envolve, deixa-se afetar pelas ações do mundo. No dizer de Dorothe Solle (1996), a presença de Deus nunca é presença observadora; é dor ou alegria de Deus.

\section{A mística como êxtase do homem; o pathos como êxtase de Deus}

Definida pela teologia clássica como cognitio Dei experimentalis, a mística é testemunho-linguagem nascida de uma experiência radical: "aquela da unidade do mundo com o supremo Princípio ou do homem com Deus.” (BOFF, 1983, p. 16). O transfundo de tal experiência é uma outra experiência não menos fundamental, qual seja, a da dualidade e da separação eu-mundo, Deus criação, uno-múltiplo. 
Como chegar a tal unidade? Como vencer os absismos de tais separações? Para Leonardo Boff, a resposta advém de duas vias arquetípicas com suas respectivas linguagens.

A primeira resposta vem do que o teólogo católico chamou de mística do desnudamento, a experiência do esvaziamento pleno, do esquecimento de si, do perder-se no Uno. Em tal resposta vige o silêncio. A experiência não se diz, vive-se. A segunda resposta diz respeito à mística de inserção no mundo. Aqui o mundo se apresenta como lugar da busca insaciável de Deus. Deus é a intimidade do mundo, a luminosidade de cada ser. Ou seja, segunda tal perspectiva, na mística há uma unidade que se dá seja imergindo em Deus, seja imergindo no mundo. A dialética seria o instrumento para articular tal unidade na diversidade, posto que na linguagem dialética tudo aparece em sua dinâmica con-juntiva, em marcha coincidencial (BOFF, 1983, p. 17).

Bingemer nomeou essas duas respostas como mística de olhos fechados e mística de olhos abertos, esta última em clara referência à noção de mística em Joahann Baptist Metz (2007). Afirma Bingemer (2013, p. 332): "O místico de olhos fechados vive, com inusitadas profundidade e consciência, a viagem sem fim do encontro com Deus que cada um inicia desde o primeiro dia da existência.” Tal mística teria sido refletida e desenvolvida por grandes mestres da vida espiritual como São João da Cruz e Santa Teresa. O místico de olhos abertos, de outro lado, quer perceber a realidade porque sabe que a última dimensão do real está habitada por Deus. "Mergulha nas situações humanas, dilaceradas ou felizes, procurando a presença de Deus que atua danda vida e liberdade.” (BINGEMER, 2013, p. 333).

O elemento peculiar da compreensão de hescheliana sobre a mística derivada do profetismo bíblico parece deslocá-la do eixo humano-divino para o eixo divino-humano. Segundo Heschel, o profeta não tateia à procura de Deus. É Deus quem está à sua procura. É em tal contexto que Heschel (1975, p. 253) dirá que a experiência mística é "um voltar-se do homem para Deus; o ato profético é um voltar-se de Deus para o homem.” No ato profético adquire-se um insight de 
Deus na vida humana; na experiência mística, um insight do humano na vida de Deus. Desta forma, a experiência mística seria um êxtase do humano; a revelação um êxtase de Deus. Ou seja, Heschel enfatiza o movimento processional divino em direção ao mundo humano. A resposta humana não se traduziria na aspiração de tornar-se um com Deus, mas tornar-se mais um para Deus, ao fazer-se encontradiço no movimento pelo qual Deus se põe à procura do ser humano.

Se a experiência mística em sua vertente especulativa ou mistérica, conforme os termos de Lima Vaz (2000), se caracteriza por uma processão do humano em direção ao divino, um movimento exotérico pelo qual o humano vai a Deus, o profeta hescheliano é precisamente aquele que se esforça para fugir deste movimento. Na mística há um voltar-se para Deus, no ato profético há um voltar-se de Deus em direção ao ser humano. Para Heschel, o primeiro é um ato na vida do homem, o segundo é um ato na vida de Deus.

O profeta não tateia à procura de Deus. A procura de Deus pelo homem, não o homem à procura de Deus, é o que se imaginava ser o principal evento na história de Israel. Isto está no âmago de todos os conceitos bíblicos: Deus não é um ser separado do homem e que deve ser procurado, mas um poder que busca, segue e apela ao homem. O caminho para Deus é um caminho de Deus. A religião de Israel originou-se por iniciativa de Deus, mais propriamente do que pelos esforços do homem. Não foi uma invenção do homem, mas uma criação de Deus; não um produto da civilização, mas seu próprio domínio. O homem não teria conhecido Deus se não tivesse ele se aproximado do homem. A relação de Deus com o homem precede a relação do homem com ele. (HESCHEL, 1975, p. 253).

\section{Portanto,}

A experiência mística é voltar-se o homem para Deus; o ato profético é voltar-se Deus para o homem. A primeira é, antes de tudo, um evento na vida do homem, contingente na aspiração e inciativa do homem; o segundo é, antes de tudo, um evento na vida de Deus, contingente na compaixão e iniciativa de Deus. (HESCHEL, 1975, p. 253).

Assim sendo, o que a consciência profética nos ensina é que a experiência de Deus não é um ato de experiência propriamente dito, mas um ato de ser experimentado, de estar exposto, de ser subjugado e tomado por Aquele que está à procura dos seus filhos e filhas, sobretudo os que vergam sob o peso da injustiça e 
da dor. Nesse sentido, o ato profético se aproxima da mísitica de olhos abertos, como vimos acima. Por essa razão, o profeta hescheliano é o oposto do homo apathetikos. Ele é o homo simpathetikos. O pathos está sobre ele, movendo-o, quebrando-o como uma tempestade, infundindo-lhe força para lutar com o mundo (HESCHEL, 2001, p. 395). Para Heschel, o que distingue a religião simpática não é a autoconquista, mas a autodedicação, não a supressão da emoção, mas seu redirecionamento, não a subordinação silenciosa, mas a ativa cooperação com Deus; não um amor que aspira ao ser de Deus em si mesmo, mas uma harmonia da alma com a preocupação divina. Portanto, ser um profeta significa identificar sua preocupação com a preocupação de Deus.

Ou seja, a simpatia não diz respeito a meros sentimentos, mas a ação que mitiga a miséria do mundo, a injustiça da sociedade, a alienação dos povos. Somente a ação aliviará a tensão entre Deus e o ser humano. Ambos, pathos e simpatia, a partir das situações concretas, são demandas mais do que cumprimentos. A simpatia profética não é um deleite, não é o objetivo, mas um desafio, um compromisso, um estado de tensão, de consternação e mesmo um desânimo. Berkovitz resume bem a teologia do pathos e a resposta simpática heschelianas:

De acordo com sua teologia do pathos, a ação humana evoca o pathos divino; de acordo com sua religião da simpatia, a compaixão divina evoca a simpatia profética. O homem afeta Deus e Deus afeta o profeta. No diálogo entre Deus e o homem, Deus responde com pathos, no diálogo entre o profeta e Deus, o profeta responde com simpatia. (BERKOVITZ, 1964, p. 70, tradução nossa).

À unio mística, o profeta hescheliano propõe a unio simpathetika. Nela não há fusão, não há assimilação do eu humano pelo Tu divino. O profeta, como diria Heschel, permanece em pé ao sofrer o pathos. Não há, no dizer de Leone (2002, p. 120), "uma identidade entre o ser humano e o divino, mas a vida do profeta foi transformada para sempre". 
A unio simphatetica tem aqui menos um sentido psicológico e mais teológico (ALMEIDA, 2015). Não se trata de um estado da alma, mas do envolvimento divino na história humana. Não se trata do êxtase humano, mas do êxtase revelador divino. Nesse sentido a noção de pathos divino é tão central na compreensão profética quanto o é a ideia do humano feito à imagem de Deus na compreensão da criação. Daí porque Heschel, embora afirme a radical alteridade divina, fruto da sua compreensão de que a revelação se dá como processão divina em direção ao mundo humano, ao mesmo tempo afirme que a ideia de Deus como totalmente outro é avessa à compreensão profética, dado que Este está em constante movimento intencional e transitivo em direção ao mundo humano.

Isso explica porque para Heschel algumas categorias fundamentais da compreensão do fenômeno religioso, tais como a noção de numinoso, podem ser até interessantes como metáforas para expressar a distância entre Deus e um ser humano iludido com sua autopretensão de claridade, mas na tradição profética tais metáforas não têm entrada. Ela é avessa à ideia de um Deus silencioso e envolto nas nuvens do mistério, dado que o pathos divino é a categoria central desse universo. Segundo Heschel, longe de ser uma categoria irracional, a noção de pathos é uma espécie de estado no qual o profeta se vê quando emocionalmente afetado pela divina presença. Torna-se então compreensível porque Abraão teria experimentado Deus não como terror numinoso, mas como a plenitude de um cuidado divino.

Portanto, o abismo que separa o finito do infinito, que separa o ser humano de Deus está transcendido pelo pathos. Para Heschel, o homem não é apenas uma imagem de Deus, ele é uma perpétua preocupação de Deus. Portanto, o ser humano está para além de uma simples criatura de Deus. "Ele é um parceiro, um consorte, um fator na vida de Deus." (HESCHEL, 2001, p. 292, tradução nossa). Desta forma, a singularidade e riqueza de significados implícitos na noção de pathos divino, e seus significados essenciais para o entendimento da situação religiosa, levam-nos a considerá-lo como uma categoria teológica sui generis (HESCHEL, 2001, p. 296). A 
profecia, assim, seria uma espécie de lembrança de que a relação entre Deus e seres humanos é da ordem de um pacto, jamais de um contrato. Nas palavras de Heschel,

O divino pathos é a unidade do temporal e o eterno, do sentido e do mistério, do metafísico e do histórico. É a base real da relação entre Deus e o homem, a correlação Criador e criatura, do diálogo entre o Santo de Israel e seu povo. O característico do profeta não é prever o futuro, mas ter insights no presente pathos de Deus. (HESCHEL, 2001, p. 298, tradução nossa).

\section{Conclusão}

O pensamento teológico judaico tem exercido forte influência sobre a teologia cristã sobretudo a partir do pós-guerra. A figura de Abraham Heschel é um dos exemplos dessa marca judaica nas páginas da teologia cristã. O caso Moltmann evidencia a força desta influência. Sua teologia nascida dos estertores do holocausto, encontrou na teologia profunda de Heschel uma de suas grandes fontes de interlocução. A teologia profunda de Heschel, com sua profunda crítica à incapacidade do mundo moderno de responder paticamente aos sofrimentos da civilização técnica, ressignificou a tradição do profetismo bíblico e abriu as janelas para a redescoberta da ideia de pathos como o coração da noção judaica de Deus. As teologias políticas, a teologias da esperança e as teologias da libertação foram fortemente influenciadas por essa nova compreensão. Há que empreender caminhos na pesquisa dessa fonte judaica das teologias contemporâneas.

A unio mística é uma expressão que vem quase imediatamente à cena quando somos conduzidos aos estudos sobre mística. A união com o divino é o elemento teleológico por excelência do movimento ascensional da alma em direção a Deus. A ideia hescheliana do pathos divino por si só já nos remete ao horizonte místico, dado que o elemento histórico, vivencial, afetivo/cognitivo, afigura-se como constituinte da sua noção de pathos. Tal noção, mais que um atributo ou conceito, é da ordem de um afetamento, de um ser atravessado pela intencionalidade e concernência divinas. Ora, é-nos possível pensar que outras compreensões da palavra mística possam advir daí. Por essa perspectiva, a mística 
não seria apenas o caminho ascensional ao alto, o tornar-se um com Deus, mas o movimento horizontal de resposta simpatética às dores divinas nas dores do mundo. Trata-se de tornar-se um para Deus.

Ainda mais, tal noção pática recoloca a ideia de mística do horizonte de um procurar, encontrar, unir-se e silenciar, para o horizonte de um tornar-se encontradiço, ser achado, descobrir-se tocado pela concernência divina na chave de um compromisso, de um estado tensional de consternação. A mística do pathos fala do humano como um ser não de necessidades apenas, mas como um ser de potencialidades criativas. Um parceiro, um consorte, um fator divino no enfrentamento das agonias e injustiças do mundo. Trata-se de uma mística de olhos abertos. Uma mística simpatética.

\section{REFERÊNCIAS}

ALMEIDA, Edson. F. A noção de pathos divino em Abraham J. Heschel. Interações, Belo Horizonte, v. 10, n. 17, jan./jun. 2015.

BERKOVITZ, Eliezer. Dr. A. J. Heschel's theology of pathos. Tradition, v. 6, n. 2, p. 67104, Spring-Summer 1964.

BINGEMER, Maria. C. O mistério e o mundo: paixão por Deus em tempos de descrença. Rio de Janeiro: Rocco, 2013.

BOFF, Leonardo. Mestre Eckhart : a mística de ser e não ter. Petróopolis : Vozes, 1983.

GAMBERINI, Paolo. Pathos e logos in Abraham J. Heschel. Roma: CittàNuova, 2009.

HESCHEL, Abraham, J. A passion for truth. New York: Farrar, Straus and Giroux, 1973.

HESCHEL, Abraham. Deus em busca do homem. São Paulo: Paulinas, 1975.

HESCHEL, Abraham. The ineffable name of God: man. New York: The Continuum International Publishing Group, 2005.

HESCHEL, Abraham. The profhets. First perennial classics edition. New York: HarperCollins Publishers Inc, 2001. 
LEONE, Alexandre . Torá, mística e razão em Heschel. In: ROANI, Gerson;

NASCIMENTO, Lyslei (Org.). Estudos judaicos, Torá. Rio de Janeiro: Oficina Raquel, 2014 .

LEONE, Alexandre. Convergências entre a teologia protestante da libertação e o pensamento judaico, na obra de Abraham Joshua Heschel. In: RIBEIRO, Claudio (Org.). Teologia protestante latino-americana: um debate ecumênico. São Paulo: Terceira Via, 2018.

LEONE, Alexandre. Mística e razão: dialética no pensamento judaico. São Paulo: Perspectiva, 2011.

LEONE, Alexandre. A imagem divina e o pó da terra: humanismo sagrado e crítica da modernidade em A. J. Heschel. São Paulo: Humanitas; Fapesp, 2002.

LEONE, Alexandre. A mística judaica refletida na obra de Heschel. Numen, Juiz de Fora, v. 10, n. 1 e 2, 2007.

LIMA VAZ, Henrique. C. Experiência místia e filosofia na tradição ocidental. São Paulo: Loyola, 2000.

LUTERO, Martinho. Obras selecionadas. São Leopoldo: Sinodal; Porto Alegre: Concórdia, 2003. (v. 8).

METZ, Johann. B. Memoria passionis: una evocación provocadora em una sociedad pluralista. Santander: Sal e Terra, 2007.

SOLLE, Dorothee. O sofrimento. Petrópolis: Vozes, 1996. 